\title{
Kaji Eksperimen lengkungan Sudu Turbin Angin Savonius Tipe-U
}

\section{Study the U-type Savonius Wind Turbine Blades Experiment}

\author{
Delffika Canra ${ }^{1)}$, Meri Rahmi ${ }^{1)} \&$ Ikhsan ${ }^{2)}$ \\ ${ }^{1)}$ Departemen Teknik Mesin, Politeknik Negeri Indramayu,Jl. Lohbener Lama no. 8 \\ Lohbener Indramayu Jawa Barat, 45252. Indonesia. delffika.canra@gmail.com, \\ meri@polindra.ac.id \\ 2) Politeknik Negeri Padang Kampus Limau Manis Padang Telp. 0751-72590 Fax. 0751- \\ 72576 Politeknik Negeri Padang ikhsan@pnp.ac.id,
}

\begin{abstract}
Wind energy sources in coastal areas of Indonesia are generally one of the potential renewable energy sources (renewable energy resources) that are abundant, environmentally friendly and renewable. Savonius wind turbines can produce relatively high torque even at low wind speeds. Because it is very well developed to produce electrical energy. To get a large amount of electrical power, a large turbine construction is also needed which also requires a large amount of money, of course. For this reason, the dimensions of this wind turbine construction need to be developed, known as aspect ratio (Ar). Ar which has been studied is the cross section of the blade, as well as other values. Whereas the arch depth or blade length of type U is still likely to be studied. Therefore it is necessary to do research on type $U$ blade arcs to get more power than before. Experimental method by making a prototype savonius type $U$ wind turbine with 2 blades. The parameters varied only in terms of the ratio of arc length and blade cross section, other parameters followed the previous study. The expected experimental results get the aspect ratio (Ar) of the best blade in capturing wind energy and producing large electrical power.
\end{abstract}

Keywords : Wind Turbine, savonius, U-type, aspect ratio, arc length of blade

\section{PENDAHULUAN}

Sumber energi angin didaerah pesisir Indonesia umumnya merupakan salah satu potensi sumber energi terbarukan (renewable energy resources) yang berlimpah, ramah lingkungan dan bersifat renewable. Kecepatan angin di Indonesia secara umum rata-rata $3-7 \mathrm{~m} / \mathrm{s}$ yang tergolong kecepatan angin rendah. Untuk memanfaatakan potensi angin ini, turbin yang terbaik digunakan adalah turbin angin savonius karena dapat berputar pada kecepatan angin rendah.

Kelebihan turbin angin savonius dapat menghasilkan torsi yang relatif tinggi meskipun pada kecepatan angin rendah. Karena itu sangat baik sekali dikembangkan untuk menghasilkan energi listrik. Banyak sekali penelitian yang sudah dilakukan untuk mengembangkan konstruksi turbin angin ini dan terus dikembangkan untuk menghasilkan daya listrik yang optimal. Pengembangan konstruksi yang sudah dilakukan adalah memvariasikan bentuk sudu, jumlah sudu, sudut sudu, tingkat sudu (multi stage), penahan (shield) dan pengarah (deflector), sehingga banyak sekali jenis sudu yang ada pada turbin ini mulai dari tipe U (bucket) yang merupakan tipe sudu awal ditemukan atau konvensional, tipe L, sudu miring (twisted-blade), sudu bertingkat dan lainnya.

Untuk mendapatkan daya listrik yang besar diperlukan konstruksi turbin yang besar juga dimana memerlukan biaya yang besar juga tentunya. Untuk itu perlu dikembagkan dimensi dari konstruksi turbin angin ini yang dikenal dengan aspect ratio(Ar). Ar yang sudah diteliti adalah penampang sudu, serta nilai parameter lainnya. Sedangkan kedalaman lengkungan atau panjang busur sudu pada tipe $U$ masih berpeluang diteliti. Oleh karena itu perlu dilakukan penelitian pada busur sudu tipe $U$ untuk mendapatkan daya yang lebih besar dari sebelumnya. 


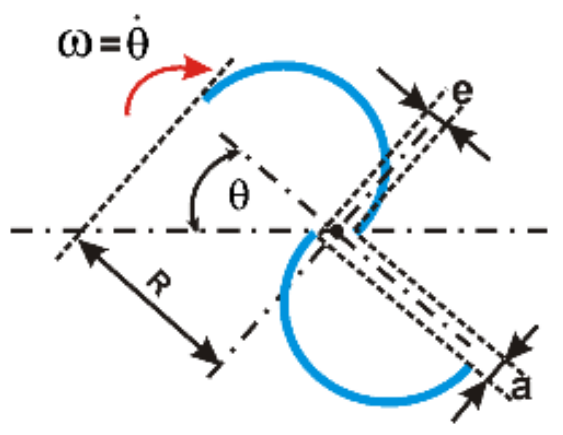

Gambar 1. Skema nilai parameter geomatrikal sudu turbin savonius

Penelitan yang dilakukan oleh Mohamed Hasan A. M dalam desertasinya pada tahun 2011 dengan judul "Design Optimazation of Savonius and Wells Turbines", mengungkapkan bahwa ada beberapa metoda untuk meningkatkan performa dari turbin angin savonius tipe $\mathrm{U}$ (conventional savonius rotors). Pertama adalah menempatkan deflecting plate didepan sudu turbin. Hal ini meningkatkan $\mathrm{Cp}$ (Coefficient of Power) sebesar $20 \%$. Metoda kedua yakni multi steps atau sudu bertingkat. Sudu ini dapat bergerak awal dengan baik (good selfstarting) akan tetapi mengalami penurunan Cp sebesar $30 \%$. Ketiga yakni Guide vanes dimana Cp yang dihasilkan 3 sudu lebih kecil dibandingkan 2 sudu. Metoda ini meningkatkan torsi pada TSR (Tip Ratio Speed) 0 hingga 0,3 akan tetapi menurunkan torsi apabila TSR melebihi dari 0,3. Oleh karena itu sudu ini tergantung sekali dengan kecepatan angin. Metoda yang keempat adalah twisted-blade (sudu miring), $\mathrm{Cp}$ yang dihasilkan meningkat 27\%, sedangkan kelemahan dari sudu ini adalah butuh biaya mahal dalam pembuatan sudu. Kelima, sudu turbin menggunakan guide-box tunnel sebagai penahan (deflector) angin untuk mencegah sudu berbalik (returning blade). $\mathrm{Cp}$ meningkat $50 \%$ pada 3 sudu, kelemahannya hanya pada konstruksi yang kompleks. Yang keenam adalah memodifikasi sudu dengan cara memberikan nilai parameter geometrikal yakni nilai overlap dan sudut antara sudu (lihat Gbr.1). Hal ini meningkatkan $\mathrm{Cp}$ sebesar $60 \%$, dan menghasilkan vibrasi yang besar. Metode yang keenam selalu digunakan dalam mendesain sudu turbin karena sudah terbukti meningkatkan $\mathrm{Cp}$ lebih signifikan dari desain sudu konvensional.

M. Haydarul H. dkk pada tahun 2013 dengan judul penelitian "Rancang Bangun Turbin Angin Vertikal Jenis Savonius dengan Variasi Jumlah Blade Terintegrasi Circular Shield untuk Memperoleh Daya Maksimum", mendapatkan nilai $\mathrm{Cp}$ yang signifikan yakni rata-rata $80 \%$ dibandingkan dengan sudu savonius tipe $\mathrm{U}$ konvensional.

Penelitian ini menggunakan metode yang kelima yakni menggunakan guide-box tunnel (kotak laluan angin), hanya saja dimodifikasi berbentuk silinder (Circular Shield). Nilai parameter geometrikal yang dipakai adalah nilai overlap sebesar $20 \%$ dari diameter endplate. Kemudian aspek rasio sudu adalah $1: 4$. Pada penelitian ini juga membuktikan bahwa peforma sudu yang terbaik adalah pada saat jumlah sudu sebanyak 2 dibandingkan dengan jumlah sudu yang lebih dari 2. Hal ini diasumsikan oleh peneliti dikarenakan beban material mempengaruhi putaran sudu.

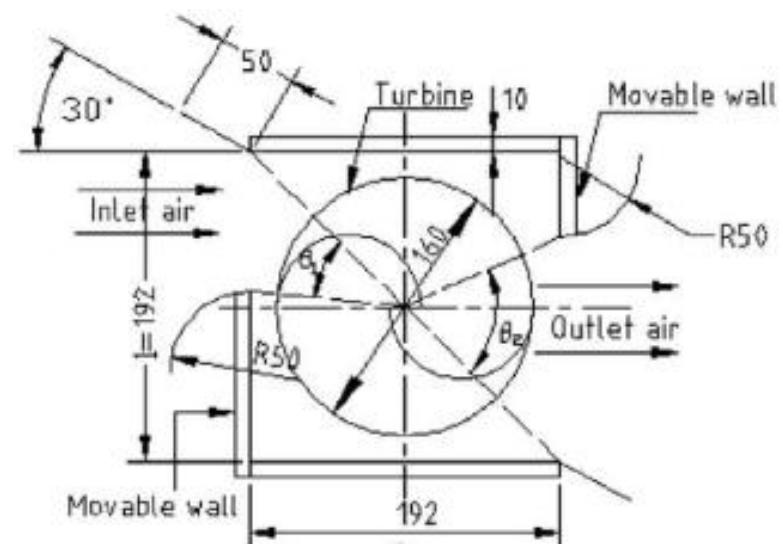

(a) 


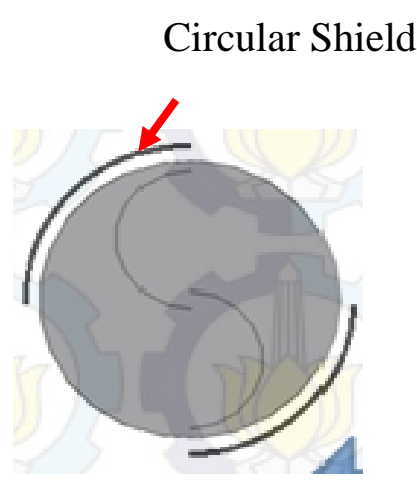

(b)

Gambar 2. Skema turbin angin menggunakan (a) Guide-box tunnel (b) Circular Shield

Penelitan ini bertujuan untuk mencari aspect ratio (Ar) lengkungan sudu terbaik untuk penyerapan energi angin dan menghasilkan daya listrik yang lebih besar.

\section{METODOLOGI}

1. DesainTurbin dan Pembuatan Prototipe.

Dimensi sampel awal didesain seperti yang terlihat pada gambar 3 yakni lebar penampang sudu adalah $100 \mathrm{~mm}$, diameter endplate $200 \mathrm{~mm}$, celah untuk overlap ratio adalah $20 \mathrm{~mm}$ dan $10 \mathrm{~mm}$, dan radius sudu awal adalah $50 \mathrm{~mm}$. Tinggi sudu prototipe adalah $400 \mathrm{~mm}$. Ukuran lengkungan sudu dibuat bervariasi untuk kebutuhan eksperimen.

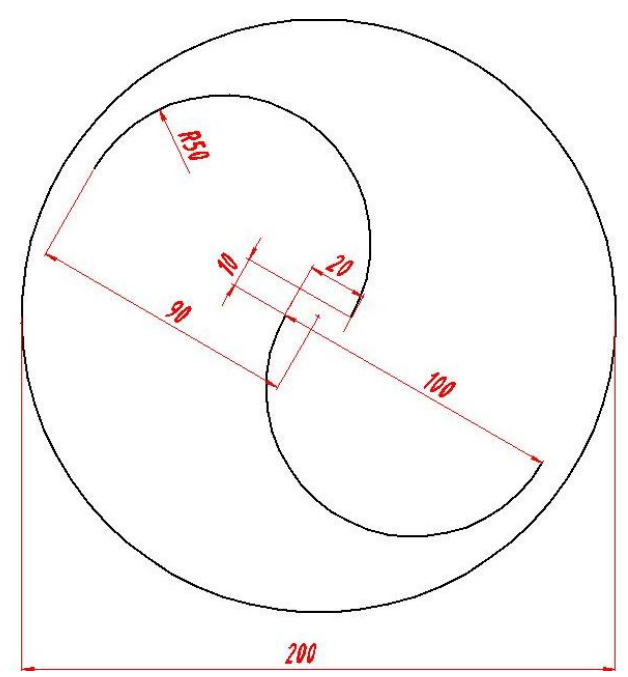

Gambar 3. Dimensi sudu turbin angin awal.

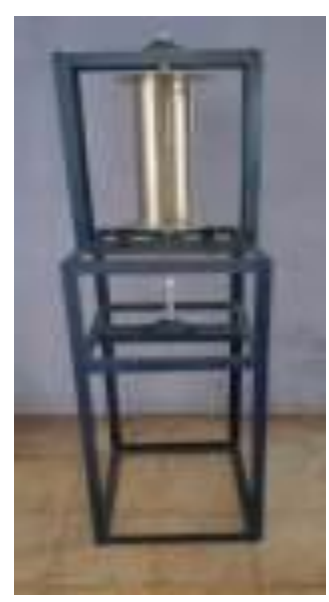

Gambar 4. Prototipe Turbin Angin

2. Prosedureksperimen.

Percobaan akan dilakukan dengan memvariasikan panjang busur yakni dengan memvariasikan besar radius sudu sedangkan lebar penampang sudu konstan. Variasi radius yang direncanakan adalah radius 60 $80 \mathrm{~mm}$ dengan resolusi $5 \mathrm{~mm}$.

Kecepatan angin yang digunakan pada simulasi adalah 3,6 sampai $6,0 \mathrm{~m} / \mathrm{s}$ dengan resolusi $0,4 \mathrm{~m} / \mathrm{s}$, sesuai dengan penelitian sebelumnya.

Percobaan dilaksanakan di laboratorium, mengkondisikan angin yang dapat diatur sesuai dengan kecepatan angin penelitian sebelumnya. Putaran turbin akan diukur serta listrik yang dihasilkan gengerator DC juga akan diukur seperti skema gambar 5. Antara poros turbin dan poros generator dihubungkan dengan roda gigi dengan rasio 6 $: 1$.

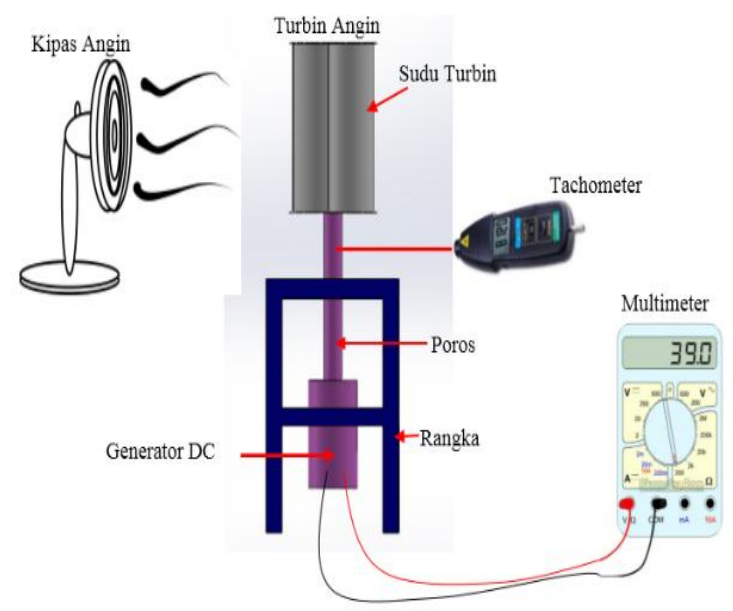

Gambar 5. Skema Percobaan 


\section{Teori Dasar}

Turbin angin savonius ditemukan pada tahun 1920 oleh SJ Savonius dengan prinsip bentuk sudu pada awalnya adalah plat tabung dibelah dua dan disatukan bersilang hingga menyerupai huruf S. Turbin angin Savonius ini dikenal dengan turbin angin savonius konvensional (Tipe U bucket).

Dengan menggunakan teori momentum Betz dimana angin kecepatan $\mathrm{v}_{1}$ melewati sebuah sudu turbin angin mengalami perubahan kecepatan $\mathrm{v}_{2}$, sehingga daya turbin yang bekerja dapat diformulasikan :

$$
P=\frac{1}{4} \rho A\left(v_{1}+v_{2}\right) \cdot\left(v_{1}^{2}-1\right.
$$

dimana $\mathrm{P}$ adalah daya turbin, $\rho$ merupakan kerapatan udara, A adalah luas sapuan,dan $\mathrm{v}$ adalah kecepatan angin.

Koefisien daya atau Coefficient of power (Cp) menentukan performa dari turbin angin tersebut dimana energi angin menentukan besarnya energi kinetik angin yang melalui sudu turbin angin tersebut dan dapat diformulasikan :

$$
P_{0}=\frac{1}{2} \rho A
$$

dimana $\mathrm{P}_{0}$ adalah daya angin. Sehingga Koefisien daya turbin dapat diformulasikan :

$$
C p=\frac{p}{P_{0}}=\frac{\frac{1}{M} \rho A\left(v_{1}+v_{2}\right) \cdot\left(v_{1}^{*}-\right.}{\frac{1}{2} \rho A v_{1}^{\mathbb{R}}}
$$

Menghitung besar torsi yang terjadi juga tidak kalah pentingnya. Torsi bisa didefinisikan ukuran keefekrifan gaya tersebut dalam menghasilkan putaran atau rotasi mengelilingi sumbu tersebut. Besarnya torsi dapat diformulasikan :

$$
T=\stackrel{\mathbb{E}}{-}
$$

dimana $\mathrm{T}$ adalah Torsi, $\mathrm{v}$ merupakan kecepatan angin, $r$ adalah lebar penampang sudu, dan $\lambda$ adalah tip ratio speed. Sedangkan tip ratio speed dihitung dengan formula :

$$
\lambda=\frac{2}{i}
$$

dimana $\mathrm{D}$ merupakan diameter sudu, $n$ adalah putaran poros/sudu dan $v$ merupakan kecepatan angin.
Sedangkan untuk mendapatkan daya generator untuk membangkit listrik adalah perlunya mengukur besarnya tegangan (V) dan arus (I) yang dihasilkan, dengan menggunakan formula :

$$
P_{g e n}=1
$$

dimana $\mathrm{P}_{\text {gen }}$ adalah daya generator listrik, $\mathrm{V}$ adalah tegangan listrik dan I adalah arus listrik.

\section{HASIL DAN PEMBAHASAN}

Dari hasil eksperimen menunjukkan bahwa semakin besar radius sudu atau semakin dangkal kelengkungan dari sudu turbin maka daya turbin juga meningkat terutama pada kecepatan angin maksimal 6 $\mathrm{m} / \mathrm{s}$ seperti pada gambar 6 .

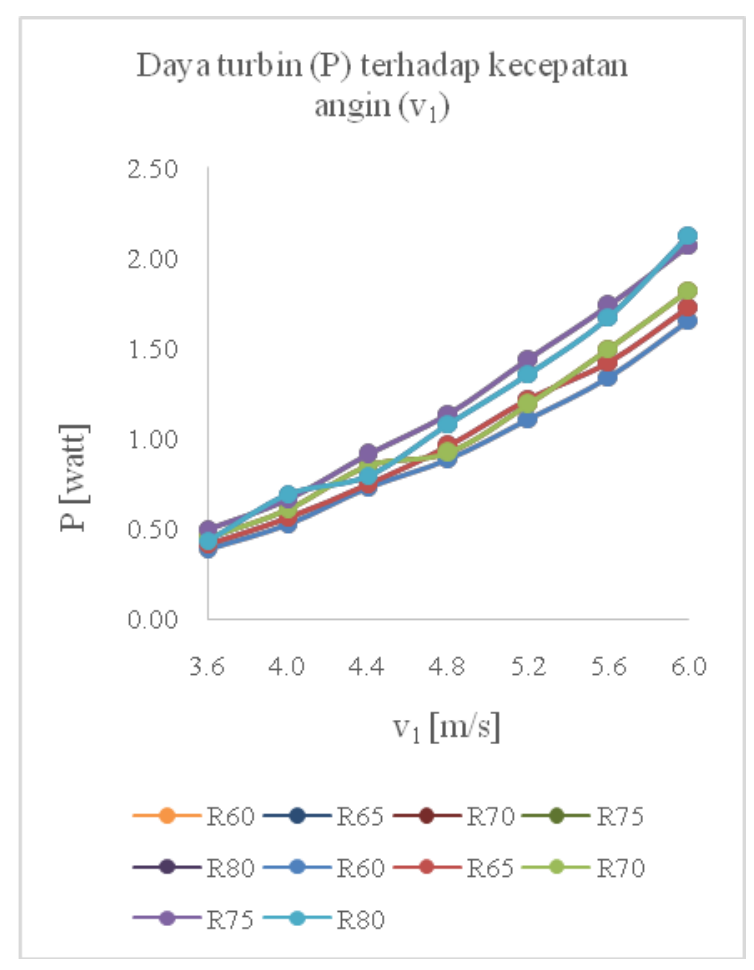

Gambar 6. Grafik hubungan Daya turbin dengan kecepatan angin

Hanya saja dari grafik, kecendrungan garis semua ukuran radius menunjukkan tren yang sama dan selisih antar radius juga belum terlalu signifikan, sehingga belum dapat disimpulkan ukuran mana yang menjadi yang terbaik. 
Begitu juga dengan grafik pada gambar 7 yang menunjukkan tren garis lurus dan stabil serta tidak ada selisih daya yang signifikan, walaupun radius 80 yang memiliki angka terbesar.

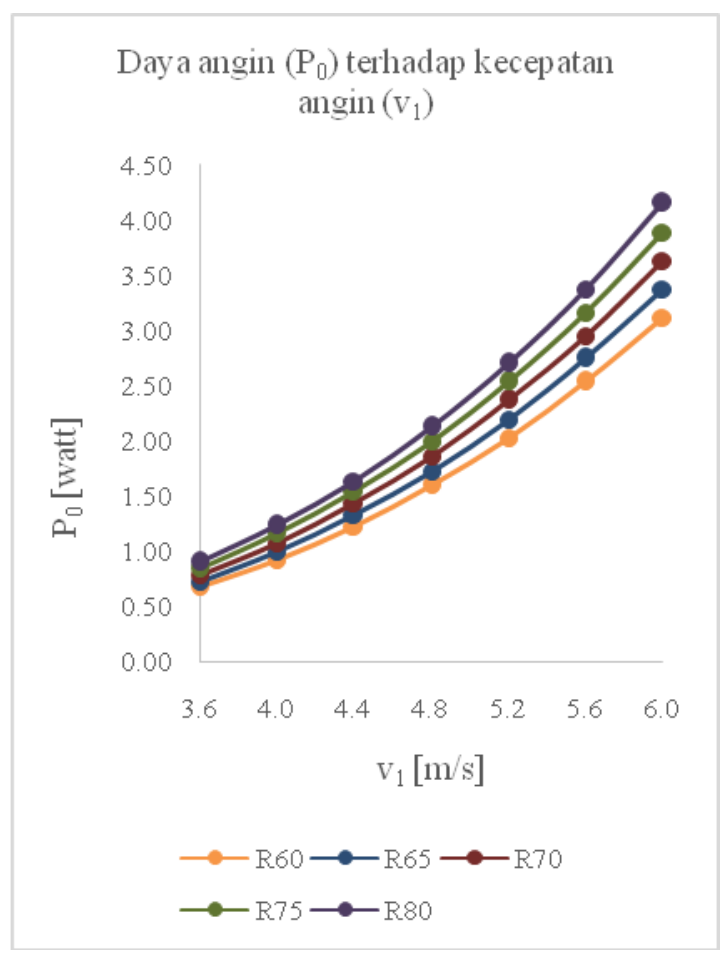

Gambar 7. Grafik hubungan Daya angin dengan kecepatan angin

Hal ini disebabkan oleh adanya penambahan besar penampang pada sudu yang juga berselisih sedikit sekali antar ukuran sudu.

Perbandingan antara daya turbin dengan daya angin yang diperlihatkan oleh grafik pada gambar 8 , menunjukkan bahwa nilai daya turbin akan meningkat sedikit lebih tinggi pada saat radius 75 dan 80 dibandingkan dengan ukuran yang dibawahnya.

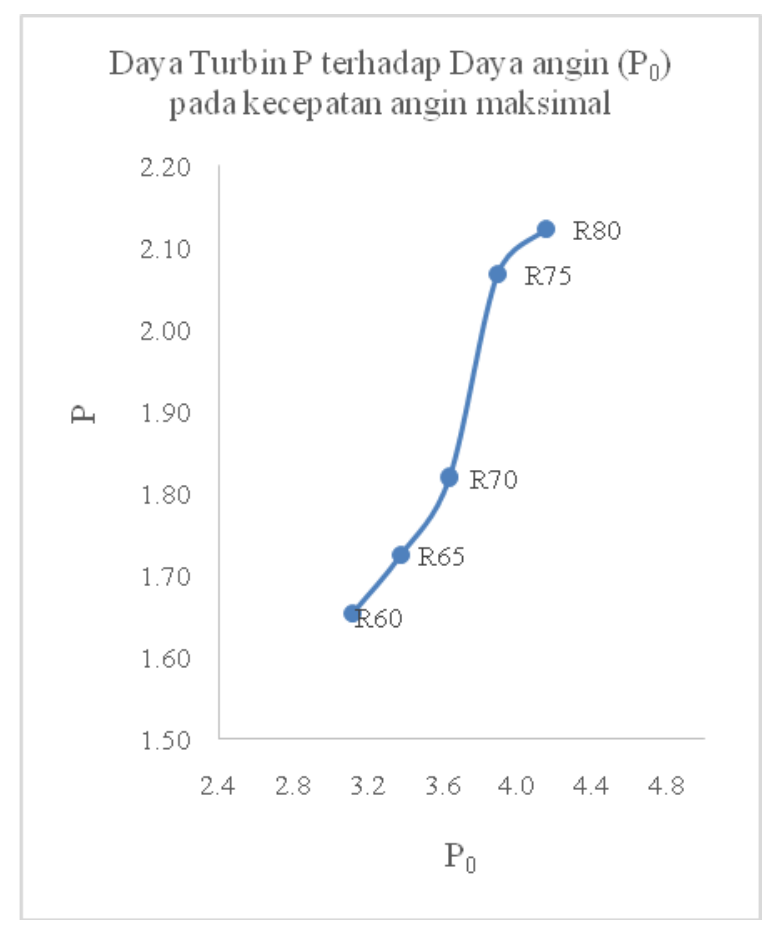

Gambar 8. Grafik hubungan Daya turbin dengan Daya angin pada saat kecepatan angin $6 \mathrm{~m} / \mathrm{s}$.

Dari grafik gambar 8 tersebut sudah memperlihatkan sedikit pengaruh dari perubahan ukuran radius.

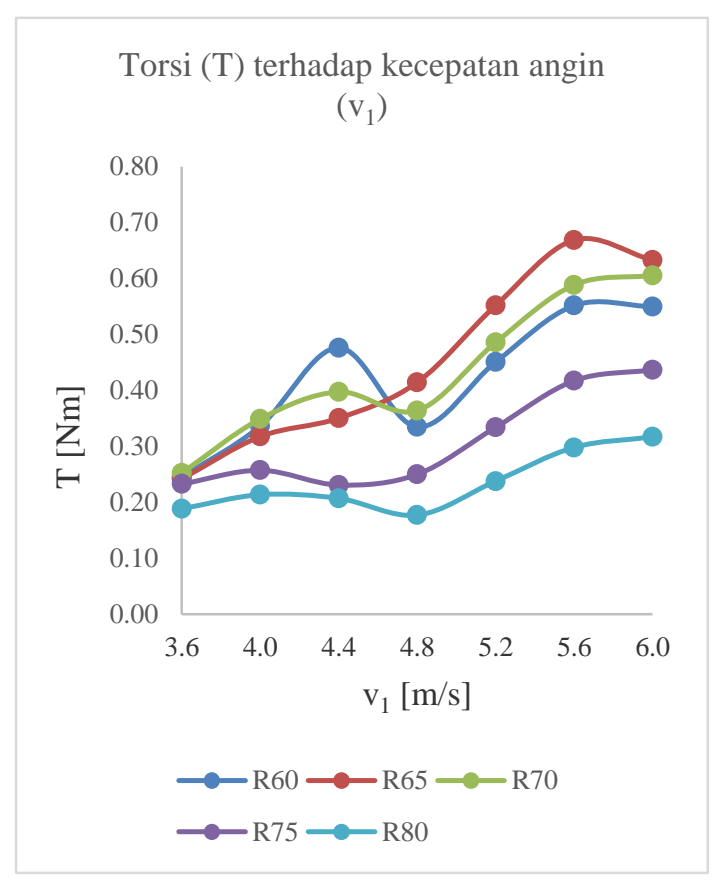

Gambar 9. Grafik hubungan Daya turbin dengan Daya angin pada saat kecepatan angin $6 \mathrm{~m} / \mathrm{s}$. 
Melihat nilai torsi dari grafik pada gambar 9, memperlihatkan bahwa torsi terkecil terjadi pada ukuran radius 80 (terbesar) dan memiliki nilai selisih sedikit lebih besar dari selisih antar sudu lainnya. Disini dapat disimpulkan juga bahwa radius terbesar mempunyai pengaruh yang lebih besar terhadap turbin angin ini.

Nilai torsi mulai stabil saat kecepatan angin mulai dari $4,8 \mathrm{~m} / \mathrm{s}$ dan seterusnya dan ada beberapak ukuran radius yang mengalami penurunan saat masuk kecepatan angin maksimal $6 \mathrm{~m} / \mathrm{s}$.

Antara poros turbin dihubungkan dengan poros generator dipasang transmisi roda gigi dengan rasio 6:1, sehingga putaran generator akan meningkat, karena generator membutuhkan kecepatan putaran yang tinggi untuk dapat membangkitkan tenaga listrik.

Kalo melihat dari grafik gambar 10, selisih antar sudu tidak terlalu signifikan akan tetapi ukuran radius 80 memiliki nilai yang besar dari awal hingga kecepatan angin maksimal dan mengalami sedikit lonjakkan pada saat masuk kecepatan angin $4,8 \mathrm{~m} / \mathrm{s}$.

Pada grafik gambar 12, menampilkan bahwa ada nilai daya generator yang naik secara signifikan yakni pada ukuran radisu 80 dan saat kecepatan angin maksimal $6 \mathrm{~m} / \mathrm{s}$. Hal ini dapat disimpulkan bahwa ukuran radius 80 merupakan ukuran sudu terbaik atau memiliki kelengkungan sudu terbaik.

Sudu turbin angin baru akan membangkitkan listrik pada saat kecepatan angin $4 \mathrm{~m} / \mathrm{s}$, akan tetapi masih terlalu kecil dan mulai stabil naik pada saat kecepatan angin $4,8 \mathrm{~m} / \mathrm{s}$ dan akan terus naik setelah kecepatan angin mencapai $6 \mathrm{~m} / \mathrm{s}$.

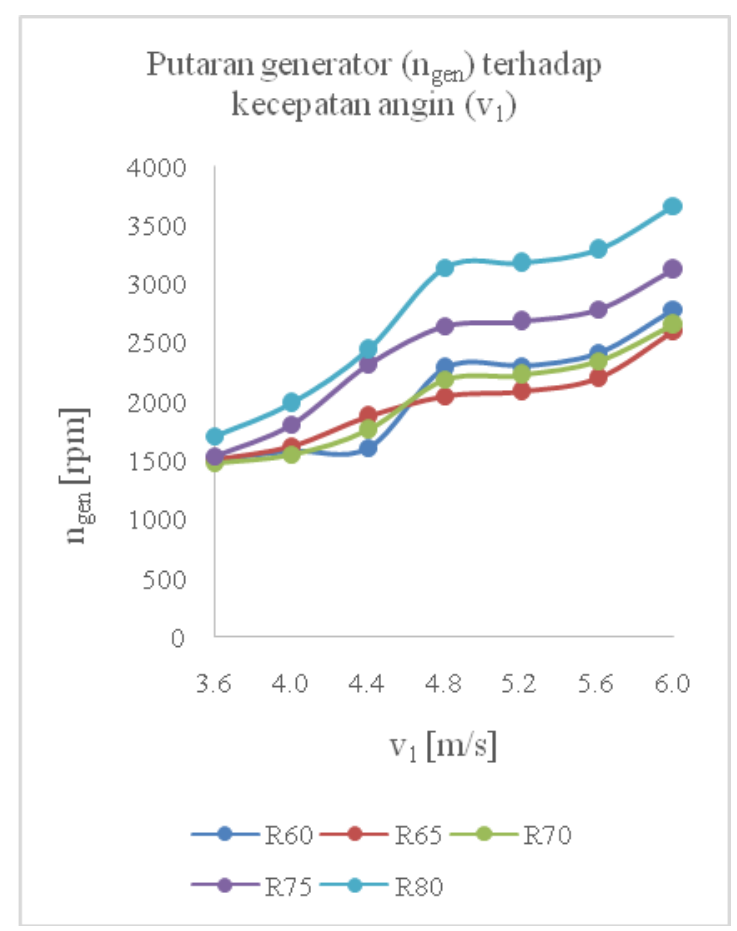

Gambar 10. Grafik hubungan putaran generator dengan kecepatan angin.

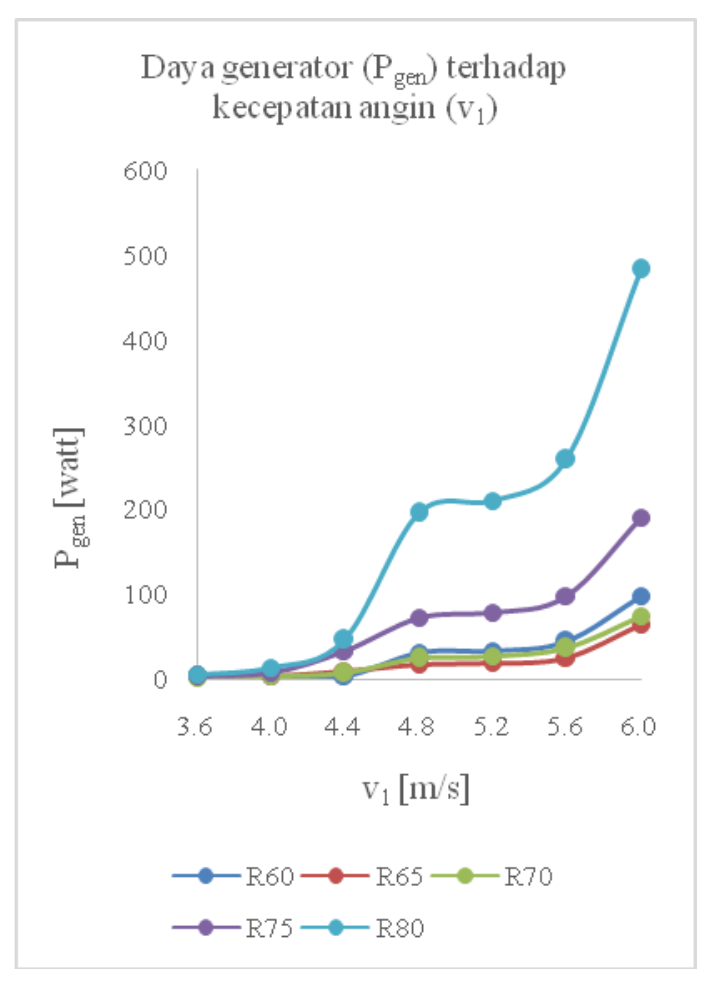

Gambar 11. Grafik hubungan daya generator dengan kecepatan angin.

\section{SIMPULAN}

Dari hasil penelitian disimpulkan bahwa ukuran atau dimensi dari sudu yang terbaik 
adalah radius 80 yang sangat mempengaruhi daya generator atau listrik yang dihasilkan. Pada dasarnya ukuran radius sudu tidak terlalu mempengaruhi daya turbin untuk menyerap angin akan tetapi bisa berpengaruh pada saat turbin diberi beban generator. Pengaruh lainnya adalah adanya rasio yang besar dari transmisi antara turbin dengan generator yakni $6: 1$.

\section{DAFTAR PUSTAKA}

[1] Rudianto D.T, Ahmadi N. 2016. RancangBangunTurbinAnginSavonius 200 Watt. Seminar NasionalTeknologiInformasidanKedirgan taraan (SENATIK). Vol :2. Hal : 71-75. Yogyakarta.

[2] Farid.

A. 2014 OptimasiDayaTurbinAnginSavoniusdeng anVariasiCelahdanPerubahanJumlahSudu - Prosiding SNST ke-5 FakultasTeknikUniversitas Wahid Hasyim. Vol : 5. Hal : 18-23. Semarang.

[3] M.Haydarul. H, Nugroho. G, Musyafa'.A. 2013. RancangBangunTurbinAnginVertikalJeni sSavoniusdengan VariasiJumlah Blade Terintegrasi Circular Shield untukMemperolehdayaMaksimum.

JurnalTeknik POMITS.; Vol : 7. Hal :1-6. Bandung.

[4] Mohamed Hasan A.M. 2011. Design Optimazation of Savonius and Wells Turbines.Disertasi. University of Magdeburg, Magdeburg;

[5] Sumiati. R.Juni 2012. PengujianTurbinAnginSavoniusTipe U sudu di LokasiPantai Air Tawar Padang. JurnalTeknikMesinPoliteknikNegeri Padang. Vol : 1(1). Hal :26-32. Padang.

[6] Zulfikardkk. 2011 KajianEksperimentalPengaruhJumlahSud uTerhadap Torsi danPutaranTurbinSavonius Type U.
JurnalTeknikMesinPoliteknikNegeri Padang. Vol : 8 (2). Hal : 13-21. Padang.

[7] BurcinDeda A. 2008. An Experimental study on improvement of a savonius rotor performance with curtaining. Experimental Thermal and Fluid Science. Vol : 32. Hal : 1637-1678.

[8] Aji, 2011. PengaruhVariasiTinggiSuduTerhadapPer formansiVertikal Axis Wind Turbine JenisSavonius Type- U. TesisJurusanTeknikMesinFakultasTeknik UniversitasBrawijaya. Malang.

[9] White F.M. 2005. MekanikaFluida. Jilid 3. EdisiKedua. PenerbitErlangga, Jakarta.

[10] Nakhoda Y.I. 2015. Rancang Bangun Kincir Angin Sumbu Vertikal Pembangkit Tenaga Listrik Portabel. Seminar Nasional Sains dan Teknologi Terapan. Vol : 3. Hal : 59-67. Institut Teknologi Adhi Tama Surabaya. 